\title{
Codon optimization, expression in Escherichia coli, and immunogenicity analysis of deformed wing virus (DWV) structural protein
}

\author{
Dongliang Fei ${ }^{1,2}$, Yaxi Guo ${ }^{1}$, Qiong Fan ${ }^{3}$, Ming Li $^{2}, \operatorname{Li~Sun~}^{2}$, Mingxiao Ma ${ }^{2}$, Yijing Li ${ }^{\text {Corresp. } 1}$ \\ ${ }^{1}$ College of Veterinary Medicine, Northeast Agricultural University, Haerbin, Heilongjiang, China \\ 2 Laboratory Animal Center, Jinzhou Normal University, Jinzhou, Liaoning, China \\ 3 Jinzhou Agricultural and Rural Comprehensive Service Center, Jinzhou, Liaoning, China \\ Corresponding Author: Yijing Li \\ Email address: 371751697@qq.com
}

Background: Deformed wing virus (DWV) is a serious threat to honey bees (Apis mellifera) and is considered a major cause of elevated losses of honey bee colonies. However, lack of information on the immunogenicity of DWV structural proteins has hindered the development of effective biocontrol drugs. Methods: We optimized the VP1, VP2, and VP3 codons of DWV surface capsid protein genes on the basis of an Escherichia coli codon bias, and the optimized genes of roVP1, roVP2, and roVP3 were separately expressed in E. coli and purified. Next, the three recombinant proteins of roVP1, roVP2, and roVP3 were intramuscularly injected into BALB/C, and the immunogenicity was evaluated by the levels of specific IgG and cytokines. Furthermore, anti-roVP-antisera (roVP1 or roVP2 or roVP3) from the immunized mice was incubated with DWV for injecting healthy white-eyed pupae for the viral challenge test, respectively. Results: The optimized genes roVP1, roVP2, and roVP3 achieved the expression in E. coli using SDSPAGE and Western blotting. Post- immunization, roVP2 and roVP3 exhibited higher immunogenicity than roVP1 and stimulated a stronger humoral immune response in the mice, which showed that the recombinant proteins of roVP3 and roVP2 induced a specific immune response in the mice. In the challenge test, data regarding quantitative real-time RT-PCR (qRT-PCR) from challenged pupae showed that the level of virus copies in the recombinant protein groups was significantly lower than that of the virus-only group at 96 h post-inoculation $(P<0.05)$. Among them, the degree of neutralisation using antibodies raised to the recombinant proteins are between approximately 2 -fold and 4 -fold, and the virus copies of the roVP3 group are the lowest in the three recombinant protein groups, which indicated that specific antibodies against recombinant proteins roVP1, roVP2, and roVP3 of DWV could neutralize DWV to reduce the virus titer in the pupae. Collectively, these results demonstrated that the surface capsid protein of DWV acted as candidates for 
the development of therapeutic antibodies against virus. 
1 Title: Codon optimization, expression in Escherichia coli, and 2 immunogenicity analysis of deformed wing virus (DWV) structural 3 protein

4

5

6

7

8

9

10 Author: Dongliang Fei ${ }^{1,2}$, Yaxi Guo ${ }^{2}$, Qiong Fan ${ }^{3}, \mathrm{Ming} \mathrm{Li}^{2}$, Li Sun${ }^{2}$, Mingxiao $\mathrm{Ma}^{2}$, Yijing $11 \mathrm{Li}^{1 *}$

12 * Corresponding Author:

13 Yijing Li E-mail: 371751697@qq.com

14 Author's Institution: 1. College of Veterinary Medicine, Northeast Agricultural University, 15 Haerbin, Heilongjiang, China; 2. Laboratory Animal Center, Jinzhou Medical University, 16 Jinzhou, Liaoning, China; 3. Jinzhou Agricultural and Rural Comprehensive Service Center, 17 Jinzhou, Liaoning, China

18 Tel.: $+86-13704061657$

19 Fax: $+86-04164673265$ 
Codon optimization, expression in Escherichia coli, and immunogenicity

\section{analysis of deformed wing virus (DWV) structural protein}

26

27 28

29

\section{ABSTRACT:}

Background: Deformed wing virus (DWV) is a serious threat to honey bees (Apis mellifera) and is considered a major cause of elevated losses of honey bee colonies. However, lack of information on the immunogenicity of DWV structural proteins has hindered the development of effective biocontrol drugs.

Methods: We optimized the $V P 1, V P 2$, and $V P 3$ codons of DWV surface capsid protein genes on the basis of an Escherichia coli codon bias, and the optimized genes of roVP1, roVP2, and roVP3 were separately expressed in E. coli and purified. Next, the three recombinant proteins of roVP1, roVP2, and roVP3 were intramuscularly injected into BALB/c, and the immunogenicity was evaluated by the levels of specific IgG and cytokines. Furthermore, anti-roVP-antisera (roVP1 or roVP2 or roVP3) from the immunized mice was incubated with DWV for injecting healthy white-eyed pupae for the viral challenge test, respectively.

Results: The optimized genes roVP 1 , roVP 2 , and roVP 3 achieved the expression in E. coli using SDS-PAGE and Western blotting. Post- immunization, roVP2 and roVP3 exhibited higher immunogenicity than roVP1 and stimulated a stronger humoral immune response in the mice, which showed that the recombinant proteins of roVP3 and roVP2 induced a specific immune response in the mice. In the challenge test, data regarding quantitative real-time RT-PCR (qRT-PCR) from challenged pupae showed that the level of virus copies in the recombinant protein groups was significantly lower than that of the virus-only group at $96 \mathrm{~h}$ postinoculation $(P<0.05)$. Among them, the degree of neutralisation using antibodies raised to the recombinant proteins are between approximately 2-fold and 4-fold, and the virus copies of the roVP3 group are the lowest in the three recombinant protein groups, which indicated that specific antibodies against recombinant 
51 proteins roVP1, roVP2, and roVP3 of DWV could neutralize DWV to reduce the

52 virus titer in the pupae. Collectively, these results demonstrated that the surface 53 capsid protein of DWV acted as candidates for the development of therapeutic 54 antibodies against virus.

55 Keywords: DWV; Codon optimization; Structural proteins; Immune responses; 56 Challenge test.

57

\section{BACKGROUND}

59

60

61

62 63

64

65

66

67

68

69

70

71

72

73

74

75

76

77

78

79

80

The western honey bee (Apis mellifera) is an important insect species for the commercial pollination of high-value crops and plays a crucial role in agricultural ecology (Garibaldi et al., 2013; Škubnik et al., 2017). However, as highlighted by the elevated losses of honey bee colonies in major beekeeping regions owing to colony collapse disorder, annual declines in honey bee populations have significantly increased over the past two decades (De Smet et al., 2012). Multiple explanations for colony losses have been proposed, including habitat degradation and the effects of pathogens, parasites, and pesticides (Tehel et al., 2019). Of the numerous infectious pathogens and infesting parasites, Varroa destructor, an ectoparasitic mite, and deformed wing virus (DWV) are regarded as serious threats to honey bee health and survival (Budge et al., 2015; Natsopoulou et al., 2017).

DWV, often considered among the most common and prevalent viruses in honey bee colonies (Dalmon et al., 2017; Gisder et al., 2018), was originally isolated from a sample of symptomatic honey bees during the early 1980s in Japan; currently, DWV is distributed worldwide, wherever Varroa mites are found (Bailey et al., 1991). DWV infection induces clinical symptoms that include deformed and crippled wings, discoloration and paralysis, and a generally shortened lifespan (De Miranda et al., 2010). DWV is a positive -strand RNA virus belong to the family Iflaviridae of the order Picornavirales (Lanzi et al., 2006). DWV is separated into three major variants: DWV-A, -B, and -C (Mordecai et al., 2016). The International Committee on Taxonomy of Viruses recognizes two master variants of DWV-A-DWV and Kakugo virus - whereas DWV-B 
81 contains Varroa destructor viruses, and DWV-C, which has only recently been

82 described, is phylogenetically distinct from both A and B types (Gisder et al., 83 2016; Mordecai et al., 2016). DWV has a single-stranded RNA genome of 84 approximately 10,000 nucleotides, and the whole genome encodes one large, 85 uninterrupted open-reading frame that is translated into polyproteins that are 86 cleaved by viral proteases to produce structural and nonstructural proteins (Bowen87 Walker et al., 1999). The three major structural proteins VP1, VP2, and VP3 from 88 one polyprotein precursor form a protomer, an elementary building block of the 89 virus capsid (Škubnik et al., 2017, Koziy et al., 2019).

90 Although DWV is regarded as one of the primary viruses that are associated with 91 honeybee colony losses (Francis et al, 2013), the effective medicine and method 92 against DWV remain limited. Antibodies, as naturally occurring proteins, play an 93 important role in neutralizing virus; thus, they have been widely utilized in the 94 prevention and control of epidemic diseases as well as for research purposes (Hu et 95 al., 2019; Nieuwkoop et al., 2019). The capability of virus neutralization and 96 antibodies titers primarily depends on antigenic immunogenicity. It is crucial to 97 identify an excellent immunogenic antigen for developing therapeutic antibodies. 98 A previous study has demonstrated that viral structural proteins not only play an 99 important role in viral infection but also possess superior immunogenicity in 100 producing neutralizing antibodies (Ojha et al., 2019; Xie et al., 2019; Mahdy et al., 101 2019); we thus speculate that the three major DWV proteins have possibly been suitable targets for effective therapeutic antibody against DWV. Presently, the VP1 recombinant fragment protein of DWV has already been successfully recombinantly expressed and used for the generation of monoclonal antibodies (Lamp et al., 2016); however, limited studies on their antigenic differences of the three structural proteins have restricted the development of therapeutic drugs. In the present study, we obtained the recombinant proteins $\operatorname{roVP} 1, \operatorname{roVP} 2$, and 109 roVP3 of DWV in E. coli using bioinformatics-based codon optimization; next, BALB/c mice were immunized with the recombinant proteins, and the immunogenicity of the three recombinant proteins was evaluated on the basis of the specific antibody level, lymphocyte proliferation, and cytokine expression.

112 Furthermore, the challenge test was performed to assess the virus - neutralizing 
113 ability of anti-roVP-antisera (roVP1 or roVP2 or roVP3). To the best of our

114 knowledge, this is the first study to express DWV structural protein genes and 115 evaluate their immunogenic potential.

116

\section{MATERIALS AND METHODS}

\section{Ethics statement and animal care}

119 All animal experiments were performed in accordance with the ethical guidelines 120 of Jinzhou Medical University, and the research protocol was approved by the 121 Animal Care and Use Committee of Jinzhou Medical University (Approval 122 number: 2018-012). The animal facility and rearing condition was based on 123 laboratory animal environment and facilities (GB14925-2010) and laboratory 124 animal feed nutrient standard (GB14924.3-2010) of China. The mice were 125 sacrificed by carbon dioxide $\left(\mathrm{CO}_{2}\right)$ inhalation.

126

\section{Strains, plasmids, virus, and antibody}

E. coli DH5 $\alpha$ and BL21 (DE3) pLysS strains were purchased from TranGen Biotech (Beijing, China). The vector pET-28a was obtained from Novagen (San Diego, CA). DWV LN8/17 strain (accession number, MF770715) was isolated,

131

132

133

134

135

136

137

138

139

140

141

142

143 identified, purified, and preserved at the author's laboratory, and the purification method of DWV particles was essentially described by Lamp et al. (Lamp et al., 2016). 6*His-tag antibody was purchased from Proteintech Group, Inc (Wuhan, China), and horseradish peroxidase (HRP)-labeled goat anti-mouse immunoglobin $\mathrm{G}(\mathrm{IgG})$ was obtained from Bioss ANTIBODIES (Beijing, China).

\section{Amplification and cloning}

Using a TIAamp viral RNA kit (TIANGEN, China), viral RNA was extracted from the purified DWV LN8/17 strain at our laboratory (MF770715). Next, first-strand complementary DNA (cDNA) was transcribed using EasyScript cDNA Synthesis SuperMix (TranGen Biotech, China), according to the manufacturer's instructions. DWV VP1, VP2, and VP3 were amplified using polymerase chain reaction (PCR) with specific primers designed based on the nucleotide sequence of the DWV LN8/17 strain ( VP1, forward primer: 5'-ATCGTATATTAAATTTRGCAGAGG- 
145 3', reverse primer: 5'-GGAGAGCCAGCAGAACC-3'; $V P 2$, forward primer: 5'AACAAGGACCTGGTAAGGTAAGTA-3', reverse primer: 5 TTATCCTAAAGTCACAAAAA-3'; VP3 forward primer: 5 CAGTGCAGGCAAAACCAGAGATG-3', reverse primer: CGGGACAAAATGGCGAGGAG-3'). PCR was conducted as follows: initial

150 151

152

153 154

155

156

157

158

159

160

161

162

163

164

165

166

167

168

169

170

171

172

173

174

175

176 denaturation at $95^{\circ} \mathrm{C}$ for $5 \mathrm{~min} ; 25$ cycles at $95^{\circ} \mathrm{C}$ for $45 \mathrm{~s}$ and $55^{\circ} \mathrm{C}$ for $40 \mathrm{~s}(V P 1)$, $51^{\circ} \mathrm{C}$ for $40 \mathrm{~s}(V P 2)$, or $50^{\circ} \mathrm{C}$ for $40 \mathrm{~s}(V P 3) ; 72^{\circ} \mathrm{C}$ for $60 \mathrm{~s}$; and final extension for 10 min at $72^{\circ} \mathrm{C}$. The PCR products were inserted into a pMD18-T cloning vector and sequenced using Synbio Techology Corporation (Suzhou, China).

\section{Codon optimization and construction of recombinant expression} vectors

$V P 1, V P 2$, and $V P 3$ sequences of the DWV LN8/17 strain were analyzed and optimized based on $E$. coli-preferred codons without changing the amino acid sequence of the corresponding proteins (Gao et al., 2015; Mansouri et al., 2013; Wang et al., 2012). High-frequency-usage codons in E. coli were the most commonly used for each of the individual amino acids (Tian et al., 2017). VP1, $V P 2$, and VP3 were subsequently reverse-translated by applying the single-most commonly used codon for each amino acid such that the final codon-optimized genes were represented by the most likely nondegenerate coding sequence, and online optimization software (http://www.jcat.de/ and http://genomes.urv.es/OPTIMIZER/) were utilized for codon design. The designed genes roVP1, roVP2, and roVP3 were synthesized by Synbio Techology Corporation (Suzhou, China) and inserted into the plasmid pET-28a $(+)$ with the respective restriction enzymes (roVP1: BamH I and Hind III; roVP2: EcoR I and Hind III; and roVP3: BamH I and Hind III), and the $6 \times$ His tag sequence is located at the $\mathrm{N}$ terminus of the recombinant plasmids.

\section{Protein expression and purification}

For each protein, BL21 (DE3) pLysS cells were transformed with the appropriate recombinant plasmids and plated on LB agar with $50 \mu \mathrm{g} / \mathrm{mL}$ kanamycin. The transformed BL21 cells were incubated at $37^{\circ} \mathrm{C}$ in an orbital shaker at $220 \mathrm{rpm}$ 
177 until an $\mathrm{OD}_{600}$ of 0.6 was obtained and then induced with $0.1 \mathrm{mM}, 0.25 \mathrm{mM}$, or 0.5 $178 \mathrm{mM}$ isopropyl- $\beta$-D-thiogalactoside (IPTG; Sigma-Aldrich, St. Louis, MO, USA) at $17930^{\circ} \mathrm{C}$ for $6 \mathrm{~h}$. To verify the expression of the target proteins, the cells were 180 collected by centrifugation and the target proteins were confirmed using $12 \%$ 181 sodium dodecyl sulfate polyacrylamide gel electrophoresis (SDS-PAGE).

182 For purifying the recombinant proteins, the cultures were harvested by 183 centrifugation at $6,000 \mathrm{rpm}$ for $30 \mathrm{~min}$ at $4^{\circ} \mathrm{C}$, and the obtained cell pellets were 184 stored at $-80^{\circ} \mathrm{C}$ for later use. All recombinant proteins in inclusion bodies were 185 purified and collected using Ni-affinity chromatography (GE Healthsystems, 186 Uppsala, Sweden), according to the manufacturer's instructions. Briefly, the 187 inclusion bodies were solubilized in $6 \mathrm{M}$ urea after being washed twice with a 188 washing buffer (1000 mL of $4 \mathrm{M}$ urea, 1\% Triton X-100, $5 \mathrm{mM}$ EDTA, $5 \mathrm{mM} \beta-$ 189 mercaptoethanol, and $50 \mathrm{mM}$ Tris- $\mathrm{HCl}$; $\mathrm{pH} \mathrm{8.5)}$ at room temperature for $30 \mathrm{~min}$. 190 The purified and denatured proteins were then refolded via dialysis in phosphate 191 buffered saline (PBS) containing urea (initial concentration: $6 \mathrm{M}$; decreased by 1 $192 \mathrm{M}$ /dialysis) and $0.5 \mathrm{M}$ arginine. The refolded proteins were then dialyzed five 193 times against the dialysis buffer to eliminate arginine, changing from $0.5 \mathrm{M}$ to $0 \mathrm{M}$ 194 buffers by the $12 \mathrm{~h}$ time-point. Recombinant roVP1, roVP2, and roVP3 proteins 195 were confirmed using SDS-PAGE and Western blotting and stored at $-80{ }^{\circ} \mathrm{C}$ until 196 further use.

197

\section{Western blot analysis}

The purified recombinant proteins were electrophoresed on $12 \%$ polyacrylamide 200 slabs along with pre-stained protein markers on adjacent lanes and transferred to a 201 polyvinylidene difluoride (PVDF) membrane. The membranes were blocked 202 overnight with $3 \%(\mathrm{w} / \mathrm{v})$ skim milk in Tris-buffered saline containing $0.05 \%$ 203 Tween-20 (TBST) at $4^{\circ} \mathrm{C}$ overnight, then incubated for $1 \mathrm{~h}$ at room temperature 204 with an anti-His tag antibody (1:3000) or an anti-DWV polyclonal antibody (1:500) 205 in blocking buffer. The anti-DWV polyclonal antibody was obtained from the mice after they were injected thrice at biweekly intervals with the purified virus particles of DWV. Simultaneously, the serum of healthy mice was also used as the negative control for incubating with PVDF membrane of the recombinant proteins. After 
209 three washes, the membranes were incubated with HRP-labeled goat anti-mouse $210 \operatorname{IgG}(1: 3000)$ for $2 \mathrm{~h}$ at room temperature. After three 5-min washes with TBST, 211 color development was performed with an ECL Western substrate (Thermo 212 Scientific, USA).

213

214 Mice immunizations

215 To evaluate the immunogenicity of the recombinant proteins, 4-6-week-old female $216 \mathrm{BALB} / \mathrm{c}$ mice (five/group) were subcutaneously immunized with a mixture of 200 $217 \mu \mathrm{L}$ each of the purified protein $(20 \mu \mathrm{g})$ and $200 \mu \mathrm{L}$ of Freund's incomplete 218 adjuvant (Sigma). All mice were then boosted twice with the same dose of 219 Freund's incomplete adjuvant at a 2-week interval with the same recombinant 220 proteins. Negative controls were injected with PBS, and positive controls with 221 purified virus particles. Serum samples were prepared prior to the first 222 immunization and 2 weeks after each immunization and stored at $-80^{\circ} \mathrm{C}$ until 223 further analysis. At 2 weeks after the last inoculation, the animals were sacrificed 224 by euthanasia to isolate splenocytes for lymphocyte proliferation in response to the 225 recombinant proteins.

226

227

228

\section{Detection of specific antibody responses using enzyme-linked immunosorbent} assay (ELISA)

229

According to a previously reported method, IgG levels in mice sera were detected 230 using ELISA (Stachyra et al., 2016). In brief, microtiter plates (Corning, USA) were coated with $50 \mu \mathrm{L}$ of the purified virus particles/well at a concentration of 5 $\mu \mathrm{g} / \mathrm{mL}$ at $4^{\circ} \mathrm{C}$ overnight. The plates were washed thrice with PBS containing $0.05 \%$ 233 TBST and blocked with $2 \%$ bovine serum albumin (BSA)-PBST for $1.5 \mathrm{~h}$ at $37^{\circ} \mathrm{C}$. After five washes, the sera samples (1:200) were added, and the plates were incubated for $1.5 \mathrm{~h}$ at $37^{\circ} \mathrm{C}$. After another five washes with PBST, the plates were incubated for $1 \mathrm{~h}$ at $37^{\circ} \mathrm{C}$ with HRP-conjugated goat anti-mice IgG (1:3000). After a final round of washes, the products were detected by adding the developing reagent tetramethylbenzidine. Absorbance was read at a wavelength of $450 \mathrm{~nm}$ $\left(\mathrm{OD}_{450}\right)$ using an ELx808 Absorbance Microplate Reader (BioTek Instruments, USA). 


\section{2}

243

244

245

246

247

248

249

250

251

252

253

254

255

256

257

258

259

260

261

262

263

264

265

266

267

268

269

270

271

272

\section{Lymphocyte proliferation assays and cytokine detection}

Two weeks after the last immunization, spleens were harvested from five mice in each group under sterile conditions. Splenocyte suspensions were prepared, and the splenocytes were cultured in 96-well plates at a density of $2.0 \times 10^{6}$ cells/well in Dulbecco's modified Eagle's medium containing 10\% fetal bovine serum. The cells were then stimulated with the purified virus particles $(10 \mu \mathrm{g} / \mathrm{mL})$, and Dulbecco's modified Eagle's medium was used alone as the negative control. According to the manufacturer's instructions, the plates were incubated in $5 \% \mathrm{CO}_{2}$ for $24 \mathrm{~h}$ at $37^{\circ} \mathrm{C}$, and then a cell-counting kit 8 solution (Vazyme, China) was added to each well and incubated for $8 \mathrm{~h}$ followed by the addition of $150 \mu \mathrm{L}$ dimethyl sulfoxide solution per well; absorbance was measured at $450 \mathrm{~nm}$ with a microplate reader. Stimulation index (SI) was calculated as the ratio of the $\mathrm{OD}_{450}$ of the stimulated cells to the $\mathrm{OD}_{450}$ of the negative controls. The cytokine levels of interleukin (IL)-2, IL-4, IL-10, and interferon gamma (IFN- $\gamma$ ) from serum samples were detected using a commercial ELISA kit (Dakewei, China), according to the manufacturer's instructions.

\section{Challenge test in the honeybee pupae}

For preliminarily assessing the ability of $\operatorname{IgG}$ antibodies from mice immunized using the recombinant proteins to neutralize DWV, we collected mice serum of the groups after the third immunization to perform the challenge test. The challenge test was modified with reference to Tehel's and Sun's methods (Sun et al., 2018; Tehel et al., 2019). Prior to the challenge test, DWV were incubated with antiroVP1- antisera, anti-roVP2-antisera, anti-roVP3-antisera, or anti-DWV-antisera (the mice immunized with DWV viral particles, and virus purification were performed as per Lamp's description (Lamp et al., 2016)) for $1 \mathrm{~h}$ at $37{ }^{\circ} \mathrm{C}$. A total of 30 healthy white-eyed pupae from the same colony in Wendilou Town of Jinzhou $\left(41.25^{\circ} \mathrm{N}, 121.11^{\circ} \mathrm{E}\right)$, were randomly distributed into six groups, with each group containing 5 pupae. Next, the pupae were transferred to 48 -well microtiter plates, and each pupa in groups 1-4 was injected with $1 \mu \mathrm{L}$ of virus particles and antisera suspension containing $1 \times 10^{4}$ copies of DWV and 50-diluted antisera; the 
273 pupae of group 5 were only injected with a mixture of five antisera from the 274 immunized mice, and the pupae of group 6 were only injected with $1 \times 10^{4}$ virus 275 particles, and all the groups were maintained in incubators at $35{ }^{\circ} \mathrm{C}$ and $50 \% \mathrm{RH}$ 276 to monitor pupal development. At $96 \mathrm{~h}$ post-inoculation (p.i.), all pupae of the 277 groups were collected, then total RNA extraction was performed according to the 278 manufacturer's instructions (TranGen, China), and the extracts were stored at $-80{ }^{\circ} \mathrm{C}$ 279 until further use.

280 The quantification of the DWV titer in the samples was performed using real time 281 qRT-PCR using the TransScript ${ }^{\circledR}$ Green One-Step qRT-PCR SuperMix (TranGen, 282 China), and RT-qPCR reaction contained 75 ng RNA, $1 \times$ TransScript ${ }^{\circledR}$ Tip Green 283 qPCR SuperMix, $1 \times$ Passive Reference Dye, and 5 pmol of each primer: DWV-F1 284 and DWV-R1 (DWV-F1:5'-TAGTGCTGGTTTTCCTTTGTC-3'; DWV-R1:5'285 CTGTGTGAGTAATTGAATCTC-3') with Actin F1 and R1 (Actin-F1:5'286 CTTGGAATCGCAGATAGAATGC-3'; Actin-R1:5'287 AATTTTCATGGTGGATGGTGC-3') as the reference gene. Apis mellifera $\beta$ 288 actin, which is reported as a stable reference gene in the DWV infection, was used 289 for normalization as described by Chen (Chen et al., 2005). The qPCR protocol for both DWV and $\beta$-actin reference gene was as follows: $45^{\circ} \mathrm{C}$ for $5 \mathrm{~min}, 95^{\circ} \mathrm{C}$ for 30 291 sec, 40 cycles of $95^{\circ} \mathrm{C}$ for $5 \mathrm{sec}, 54^{\circ} \mathrm{C}$ for $30 \mathrm{sec}(\mathrm{DWV}), 55^{\circ} \mathrm{C}$ for $30 \mathrm{sec}(\beta$-actin), 292 and $72^{\circ} \mathrm{C}$ for $20 \mathrm{sec}$. The relative DWV titers of the pupae were assessed by 293

294 Statistical analysis calculating delta $\mathrm{C} t$ values $\left(\Delta \mathrm{C} t=\mathrm{C} t_{(\mathrm{DWV})}-\mathrm{C} t_{(\mathrm{actin})}\right)$.

295 296

297 298 299

300

301

302

303

304

All data are expressed as mean \pm standard deviation. Statistical analyses were performed using GraphPad Prism 7.0 software (GrapPad, USA). Differences in the levels of antibodies, lymphocyte proliferation, and cytokines among the various groups were evaluated using an independent samples t-test. $P<0.05$ was considered statistically significant.

\section{RESULTS}

\section{Codon optimization of $V P 1, V P 2$, and $V P 3$}

After sequencing, the full lengths of $V P 1, V P 2$, and $V P 3$ were 1248, 675, and 738 bp, encoding polypeptide of 416, 225, and 246 amino acid residues, respectively. 
305 Analysis of three structural protein genes revealed various rare codons, including 306 CTT (Leu), CTA (Leu), CGA (Arg), AGA (Arg), AGG (Arg), GGA (Gly), ATA 307 (Ile), CCC (Pro), TCA (Ser), and ACA (Thr) in E. coli. To obtain high expression 308 level of the recombinant VP1, VP2, and VP3 proteins, roVP1, roVP2, and roVP3 309 were synthesized so as to replace the low-frequency-usage codons with high310 frequency ones in E. coli. Results indicated that 71\% (298/416; roVP1), $72 \%$ $311(162 / 225$; roVP2), and $73 \%(180 / 246$; roVP 3$)$ of the codons were optimized 312 according the codon bias of the E. coli genome (Table S1). The sequence 313 alignment showed that codon-optimized roVP1, roVP2, and roVP3 shared $72.8 \%$, $31472.6 \%$, and $71.4 \%$ identity with wild-type $V P 1, V P 2$, and $V P 3$. Furthermore, the 315 codon adaptation index (CAI) of the three genes increased from 0.19, 0.20, and 3160.19 to $0.94,0.95$, and 0.94 (Figure S1), respectively; further, the GC content was 317 also adjusted from $41 \%, 38 \%$, and $39 \%$ to $56 \%, 55 \%$, and $53 \%$, respectively. The 318 substitution of nucleotides did not alter their coding amino acid sequences.

319

320

321

322

323

324

325

326

327

\section{Expression and purification of the recombinant proteins}

The recombinant plasmids containing roVP 1 , roVP2, and roVP3 were transformed into E. coli BL21 (DE3) and expressed under the induction of IPTG. The recombinant proteins roVP1 and roVP3 were expressed in a soluble form and purified from the supernatant. The recombinant protein roVP2 was expressed in an insoluble form, i.e., as inclusion bodies, and was purified after solubilization in 6 $\mathrm{M}$ urea and by using Ni-affinity chromatography. SDS-PAGE analysis showed that the apparent molecular weights of the recombinant proteins were approximately 50.5 (roVP1), 29.1 (roVP2), and $32.6 \mathrm{kDa}$ (roVP3), which was in accordance with their theoretical values (Figure 1). The optimized IPTG concentrations of expression were 0.5 (roVP1: Figure 1A, lane 3), 0.1 (roVP2: Figure 1B, lane 1), and 0.25 (roVP3: Figure 1C, lane 2) $\mathrm{mmol} / \mathrm{L}$. After purification with Ni-affinity chromatography, the recombinant proteins were presented as a single band (roVP1: 334

Figure 1A, lane 5; roVP2: Figure 1B, lane 5; roVP3: Figure 1C, lane 5).

\section{Western blot analysis of the recombinant proteins}


336 To determine the expression of the recombinant proteins, Western blot analysis

337 was performed using mouse anti-His tag antibodies and anti-DWV polyclonal 338 antibodies, but the recombinant proteins didn't combine with the negative 339 control (the serum of healthy mice). The results showed that the single reaction 340 bands corresponding to the bands in SDS-PAGE could be observed in the PVDF 341 membrane, indicating the reactogenicity of the recombinant proteins roVP 1 , roVP2, 342 and roVP3 to specific antibodies (Figure 2 A-C, Figure S2).

343

344

345

346

347

348

349

350

351

352

353

354

355

356

357

358

359

360

361

362

363

364

365

366

367

\section{Immune effect comparison for serum antibody titers}

To evaluate the immunogenicity of the recombinant proteins, BALB/c mice were immunized with roVP1, roVP2, or roVP3 thrice at 2-week intervals and the total IgG antibody levels were measured using ELISA. As shown in Figure 3 and Table S2, after the first immunization, serum total IgG levels were higher in mice of the recombinant groups and group of the purified virus particles than in those of the control group $(P<0.05)$. In addition, the mice that were inoculated with the purified virus particles induced higher levels of IgG antibodies than those of the other groups. After the booster immunization, the antibody levels in group roVP3 were significantly higher than those in the roVP2 and roVP1 groups; the roVP1 group induced the lowest immune response. At 2 weeks after the last immunization, high levels of IgG were detected in the three recombinant protein groups compared with those in the control PBS group $(P<0.05)$. Although the difference between the roVP3 and roVP2 groups was insignificant $(P>0.05)$, the antibody levels were higher in the roVP3 group than in the roVP2 group, and both of them were significantly higher than those in the roVP1 group $(P<0.05)$. These results suggest that the three recombinant proteins had strong immunogenicity and that roVP3 effectively promoted the antibody levels induced in mice.

\section{Immune effect comparison for lymphocyte proliferation and cytokine}

\section{secretion}

To evaluate splenocyte proliferation in vitro, spleen cell suspensions from the mice of different groups were prepared at two weeks after the last immunization. Our data suggest that a significantly higher SI value was obtained from mice 
368 immunized with the recombinant protein groups and from the group of purified 369 virus particles than from the control groups $(P<0.05)$ (Figure 4, Table S3).

370 Moreover, the roVP2 group exhibited the highest level of lymphocyte proliferation

371 (SI=1.96 \pm 0.18$)$, which was insignificantly different from that in the roVP1 and 372 roVP3 groups; further, lymphocyte proliferation in the roVP3 group (SI $373=1.79 \pm 0.10)$ was higher than that in the roVP1 group $(\mathrm{SI}=1.72 \pm 0.12)$. These results 374 indicate that the recombinant proteins successfully stimulated the mice to promote 375 lymphocyte proliferation.

376 The levels of serum IL-2, IL-4, IL-10, and IFN- $\gamma$ in each group are shown in 377 Figure 5 and Table S4. Compared with the PBS control group, the IL-2, IL-4, IL37810 , and IFN $-\gamma$ concentrations in the recombinant protein groups were significantly 379 higher $(P<0.05)$ at 2 weeks after the last immunization. Among the recombinant 380 protein groups, the IL-2 and IFN- $\gamma$ levels were significantly higher in the roVP2 381 group than in the roVP1 and roVP3 groups $(P<0.05)$, and the mice immunized 382 with roVP3 showed significantly higher levels of IL-4 $(P<0.05)$. However, the 383 level of IL-10 was not statistically significantly different in the roVP1, roVP2, and 384 roVP3 groups $(P>0.05)$. These results show that immunization with the 385 recombinant proteins induced T-cells to secret multiple cytokines.

386

387

388

389

390

391

392

393

394

395

396

397

398

\section{The result of Challenge test in the honeybee pupae}

The aim of challenge test was to evaluate whether antisera against DWV recombinant structural protein could neutralize virus in honeybee pupae. As seen in Figure 6 and Table S5, the DWV levels in the group infected with only virus were significantly higher than other groups, indicating that DWV could massively replicate in the pupae at the $96 \mathrm{~h}$. At the same time, the DWV level in the pupae of the five-antisera-only group was significantly lower than in the pupae of any other treatment groups. From the analysis of qRT-PCR data, DWV was undetectable by qRT-PCR in the group injected with five antisera. Compared with the group injected virus particles, we detected a markedly lower relative normalized virus titer in the anti-roVP1/2/3-antisera groups and positive control group (anti-DWVantisera); all of them significantly differed from the virus particles group $(P<$ $0.05)$, suggesting that anti-roVP $1 / 2 / 3$-antisera or anti-DWV-antisera could 
400 neutralize DWV virus particles. Moreover, the anti-DWV-antisera group showed 401 the lowest virus titer in all groups (Figure 6 and Table S5). Among anti402 roVP $1 / 2 / 3$-antisera groups, the relative virus titer of roVP3 group was the lowest, 403 and it significantly differed from that in the roVPl groups $(P<0.05)$ (Figure 6, 404 Table S5). These indicated that specific antibody, which was produced in the mice 405 immunized with the recombinant proteins, could neutralize DWV and reduce the 406 virus titer in the pupae.

407

408 DISCUSSION

409 DWV is one of the most prevalent and pathogenic viruses affecting honey bee in 410 the world, and it has been directly linked to colony collapse disorder (Benaets et al., 411 2017; Jamnikar-Ciglenecki et al., 2018). At present, research of DWV is being 412 focused on the isolation and sequence analysis of the strains, the epidemiological 413 investigation of the interaction with Varroa destructor, and the establishment of a 414 rapid detection method (Bradford et al., 2017; Kevill et al., 2019; Tehel et al., 415 2019; Zhao et al., 2019). However, research on therapeutic drugs against DWV is 416 still rare. Egg yolk antibodies known as immunoglobulin Y (IgY) have been 417 widely utilized in the prevention and control of epidemic diseases associated with 418 Acinetobacter baumannii, Vibrio splendidus, the Dengue virus, noroviruses, 419 rotaviruses, and duck adenovirus 3 (Fink et al., 2017; Ghosh et al., 2018; 420 Jahangiri et al., 2019; Li et al., 2016; Yin et al., 2019). Moreover, Li sun reported 421 that specific IgY could be obtained from hens immunized with an inactivated 422 Chinese Sacbrood virus (CSBV) vaccine, which has the ability to neutralize CSBV 423 (Sun et al., 2018). Therefore, we should be able to develop novel therapeutic drugs 424 against DWV using this strategy. However, owing to lack of an efficient cell 425 culture system and limited animal models for DWVs, we were unable to obtain 426 large amounts of the viral protein to perform further research in this direction. At 427 the same time, the immunogenicity and antigenic differences among the DWV 428 structural proteins remain unclear. In this study, we successfully produced the 429 recombinant DWV proteins roVP1, roVP2, and roVP3 via expression in E. coli to 430 evaluate their immunogenicity, and Western blot analysis of the recombinant 431 proteins conducted using anti-His monoclonal antibodies and anti-DWV 
432 polyclonal antibodies confirmed the identity of the target proteins, indicating that

433 the DWV structural protein genes can be expressed in a prokaryotic system.

434 Comparing the codon usage in E. coli, we found many rare codons in the wild 435 DWV structural protein genes, and CAI values of the three target genes were only 436 approximately 0.2 ; this likely results in lower expression yields - even expression 437 failure - in E. coli. Codon optimization can improve protein production via 438 optimization of translation elongation, and previous reports have shown that a 439 codon-optimization strategy can improve the expression level of genes in many species (Chu et al., 2018; Hu et al., 2019; Nieuwkoop et al., 2019; Sun et al., 2017). In this study, the rare codons of DWV VP1,VP2, and VP3 were replaced with the most highly preferred codons, and the GC content was changed to approximately $70 \%$. In addition, the AT-rich fragment was removed to avoid

444

445

446

447

448

449

450

451

452

453

454

455

456

457

458

459

460

461

462

463 premature translation termination. After optimization, the CAI value of the three genes reached approximately 0.95 . To avoid the impact of tag proteins on the spatial conformation of the recombinant protein, we selected pET28a $(+)$ as the expression vector because the molecular weight of the His-tag protein is only approximately $0.8 \mathrm{kDa}$. SDS-PAGE showed that optimized roVP 1 , roVP2, and roVP3 were efficiently expressed in E.coli. Prokaryotic expression offers many advantages, such as simple manipulation, relatively low capital costs, and fitting mass production (Liu et al., 2018), and serves as a convenient method for obtaining large numbers of recombinant proteins; however, protein sequences of VP1, VP2, and VP3 probably exist as potential glycosilation sites as per online software analysis (http://www.cbs.dtu.dk/services/NetNGlyc/), and the influence of potential glycosilation sites on the immunogenicity requires further research.

Research has indicated that structural proteins of the virus not only play an important role in viral invasion and replication but also have excellent immunogenicity and that they are frequently selected as candidates for the development of therapeutic antibodies (Huo et al., 2018; Li et al., 2014; Stachyra et al., 2016; Wang et al., 2017). Compared with vertebrate immune systems, honey bee immune pathways lack acquired immunity (Bull et al., 2012) and cannot directly generate specific antibodies in response to an antigen. We therefore hope to prepare the antibody against DWV by the mammal in the present study, and 
464 humoral immunity is thought to be critical to evaluate the immunogenicity of the

465 three recombinant proteins. Our results showed that among the three recombinant 466 proteins, roVP3 induced the highest levels of specific IgG in the serum. IL-2 and 467 INF- $\gamma$ are mainly secreted by Th1 cells, which promote cellular immune responses, 468 and IL-4 and IL-10 are mainly secreted by Th2 cells, which promote humoral 469 immune responses (Wang et al., 2017; Zheng et al., 2019). Comparing SI values 470 and and cytokines, we speculate that roVP2 has a strong effect on cellular immune 471 responses and that roVP3 can induce a strong humoral immune response in the 472 mice, although all the three recombinant proteins could stimulate cellular and 473 humoral immune responses.

474 In the challenge test, all the anti - roVP1/2/3 - antisera could confer to the 475 pupae protection against DWV, which indicated that antisera against recombinant 476 protein of the mice possess the ability of neutralizing virus. Although co-injection 477 with anti-DWV or roVP1/2/3-antisera could reduce DW levels, whether they 478 prevent development of DWV infection need further research. In the 479 previous research, the C-terminal extension of VP3 protein folds into a globular 480 protruding $(\mathrm{P})$ domain, exposed on the surface of the virion, which contains five 481 Asp-His-Ser residues, and the $\mathrm{P}$ domain may participate in receptor-binding or 482 provide the protease, lipase, or esterase activity required for entry of the virus into 483 a host cell (Škubnik et al., 2017), and anti-roVP3 - antisera show the most 484 superior viru-neutralizing ability in challenge test; thus, we speculated that 485 anti - roVP3 - antisera inhibits virus entry into target cells by the prevention of 486 conformational changes within $\mathrm{P}$ domain or the inhibition of receptor binding. 487 These results of the challenge test provide a new idea for development of a 488 treatment strategy against DWV.

\section{CONCLUSION}

492

In summary, the present study has shown for the first time that the DWV structural proteins $V P 1, V P 2$, and $V P 3$ can be efficiently expressed in E. coli using a codon-optimization strategy. Based on the results of mice immunization 
495 experiments and challenge test, we found that the recombinant proteins roVP3 and 496 roVP2 have excellent immunogenicity in mice. After the virus were incubated with 497 the specific antibodies against DWV capsid proteins, virus copies from challenged 498 pupae reduced significantly on quantitative real-time RT-PCR detection in the 499 challenge test, which indicated that the specific antibodies against DWV capsid 500 proteins could neutralize DWV. Thus, they are promising candidate immunogens 501 for the development of therapeutic antibodies. Our research provides a novel 502 pathway for exploiting anti-DWV biological drugs and may aid further research 503 concerning the effects of DWV on honey bees.

504

505

506

References

507 Bailey L, Ball BV. 1991. Honey bee pathology (2nd Ed.). Academic Press.

508 London, United Kingdom: 113 DOI http://dx.doi.org/10.9774/GLEAF.978-1-

509 909493-38-4_2

510 Benaets K, Van Geystelen A, Cardoen D, De Smet L, de Graaf DC, Schoofs L,

511 Wenseleers T. 2017. Covert deformed wing virus infections have long-term

512 deleterious effects on honeybee foraging and survival. Proceedings of the Royal

513 Society B: Biological Sciences 284(1484): 20162149 DOI

$514 \quad 10.1098 /$ rspb.2016.2149

515 Bowen-Walker PL, Martin SJ, Gunn A. 1999. The Transmission of Deformed 516 Wing Virus between Honeybees. (Apis mellifera L.) by the Ectoparasitic 517 MiteVarroa jacobsoniOud. Journal of invertebrate pathology 73(1): 101-106 DOI $518 \quad \mathbf{1 0 . 1 0 0 6 / j i p a . 1 9 9 8 . 4 8 0 7}$

519 Bradford EL, Christie CR, Campbell EM, Bowman AS. 2017. A real-time PCR 520 method for quantification of the total and major variant strains of the deformed 521 wing virus. PLoS One, 12(12): e0190017 DOI 10.1371/journal.pone.0190017

522 Budge GE, Pietravalle S, Brown M, Laurenson L, Jones B, Tomkies, V, 523 Delaplane KS. 2015. Pathogens as predictors of honey bee colony strength in

524 England and Wales. PLoS One 10(7): e0133228 DOI 525 10.1371/journal.pone.0133228 
526 Bull JC, Ryabov EV, Prince G, Mead A, Zhang C, Baxter LA, Chandler D. 527 2012. A strong immune response in young adult honeybees masks their increased 528 susceptibility to infection compared to older bees. PLoS pathogens 8(12): 529 e1003083 DOI 10.1371/journal.ppat.1003083

530 Capucci L, Rossi C. 2006. Molecular and biological characterization of deformed 531 wing virus of honeybees (Apis mellifera L.). Journal of virology 80(10): 4998-5009 532 DOI 10.1128/JVI.80.10.4998-5009.2006

533 Chen, Y P, Higgins JA, Feldlaufer MF. 2005. Quantitative Real-Time Reverse 534 Transcription-PCR Analysis of Deformed Wing Virus Infection in the Honeybee 535 (Apis mellifera L.). Applied and Environmental Microbiology, 71(1), 436-441 536 DOI 10.1128/aem.71.1.436-441.2005

537 Chu C, Zhang W, Li J, Wan, Y, Wang Z, Duan R, Hao Q. 2018. A Single 538 Codon Optimization Enhances Recombinant Human TNF- $\alpha$ Vaccine Expression in 539 Escherichia coli. BioMed research international 2018: 1-8 DOI $540 \quad \mathbf{1 0 . 1 1 5 5 / 2 0 1 8 / 3 0 2 5 1 6 9}$

541 Dalmon A, Desbiez C, Coulon M, Thomasson M, Le Conte Y, Alaux C, Moury 542 B. 2017. Evidence for positive selection and recombination hotspots in deformed 543 wing virus (DWV). Scientific reports 7: 41045 DOI

544 De Smet L, Ravoet J, de Miranda JR, Wenseleers T, Mueller MY, Moritz RF, 545 De Graaf DC. 2012. BeeDoctor, a versatile MLPA-based diagnostic tool for 546 screening bee viruses. PLoS One 7(10): e47953 DOI 547 10.1371/journal.pone.0047953

548 Francis RM, Nielsen SL, Kryger P. 2013. Varroa-Virus Interaction in Collapsing 549 Honey Bee Colonies. PloS One 8: e0057540

550 DOI 10.1371/journal.pone.0057540

551 Fink AL, Williams KL, Harris E, Alvine TD, Henderson T, Schiltz J, Bradley

552 DS. 2017. Dengue virus specific IgY provides protection following lethal dengue 553 virus challenge and is neutralizing in the absence of inducing antibody dependent 554 enhancement. PLoS neglected tropical diseases 11(7): e0005721 DOI 555 10.1371/journal.pntd.0005721 
556 Gao CY, Xu TT, Zhao QJ, Li CL. 2015. Codon optimization enhances the 557 expression of porcine $\beta$-defensin-2 in Escherichia coli. Genet Mol Res 14(2): 558 4978-4988 DOI 10.4238/2015.may.12.1

559 Garibaldi LA, Steffan-Dewenter I, Winfree R, Aizen MA, Bommarco R, 560 Cunningham SA, Bartomeus I. 2013. Wild pollinators enhance fruit set of crops 561 regardless of honey bee abundance. Science 339(6127): 1608-1611 DOI 562 10.1126/science.1230200

563 Ghosh S, Malik YS, Kobayashi N. 2017. Therapeutics and immunoprophylaxis 564 against noroviruses and rotaviruses: the past, present, and future. Current drug 565 metabolism 19(3): 170-191 DOI 10.2174/1389200218666170912161449

566 Gisder S, Möckel N, Eisenhardt D, Genersch E. 2018. In vivo evolution of viral 567 virulence: switching of deformed wing virus between hosts results in virulence 568 changes and sequence shifts. Environmental microbiology 20(12): 4612-4628 DOI 569 10.1111/1462-2920.14481

570 Hu H, Dai S, Wen A, Bai X. 2019. Efficient Expression of Xylanase by Codon 571 Optimization and Its Effects on the Growth Performance and Carcass 572 Characteristics of Broiler. Animals 9(2): 65 DOI 10.3390/ani9020065

573 Huo Y, Wan X, Ling T, Wu J, Wang W, Shen S. 2018. Expression and 574 purification of norovirus virus like particles in Escherichia coli and their 575 immunogenicity in mice. Molecular immunology 93: 278-284 DOI 576 10.1016/j.molimm.2017.07.014

577 Jahangiri A, Owlia P, Rasooli I, Salimian J, Derakhshanifar E, Naghipour 578 Erami A, Darvish Alipour Astaneh S. 2019. Specific egg yolk antibodies (IgY) 579 confer protection against Acinetobacter baumannii in a murine pneumonia model. 580 Journal of Applied Microbiology 126(2): 624-632 DOI 10.1111/jam.14135

581 Jamnikar-Ciglenecki U, Pislak Ocepek M, Toplak I. 2018. Genetic Diversity of 582 Deformed Wing Virus from Apis mellifera carnica (Hymenoptera: Apidae) and 583 Varroa Mite (Mesostigmata:Varroidae). Journal of economic entomology 112(1): 584 11-19 DOI 10.1093/jee/toy312

585 Kevill JL, de Souza FS, Sharples C, Oliver R, Schroeder DC, Martin SJ. 2019. 586 DWV-A Lethal to Honey Bees (Apis mellifera): A Colony Level Survey of DWV 
587 Variants (A, B, and C) in England, Wales, and 32 States across the US. Viruses 588 11(5): 426 DOI 10.3390/v11050426

589 Koziy RV, Wood SC, Kozii IV, van Rensburg CJ, Moshynskyy I, Dvylyuk I, 590 Simko E. 2019. Deformed Wing Virus Infection in Honey Bees (Apis mellifera L.).

591 Veterinary pathology 56(4): 636-641 DOI 10.1177/0300985819834617

592 Lamp B, Url A, Seitz K, Eichhorn J, Riedel, C, Sinn LJ, Rümenapf T. 2016.

593 Construction and rescue of a molecular clone of deformed wing virus (DWV).

594 PloS one 11(11): e0164639 DOI 10.1371/journal.pone.0164639

595 Lanzi G, De Miranda JR, Boniotti MB, Cameron CE, Lavazza A, De Miranda 596 JR, Genersch E. 2010. Deformed wing virus. Journal of invertebrate pathology

597 103: S48-S61 DOI 10.1016/j.jip.2009.06.012

598 Li X, Jing K, Wang X, Li Y, Zhang M, Li Z, Xu Y. 2016. Protective effects of 599 chicken egg yolk antibody (IgY) against experimental Vibrio splendidus infection 600 in the sea cucumber (Apostichopus japonicus). Fish \& shellfish immunology 48: 601 105-111 DOI 10.1016/j.fsi.2015.11.024

602 Li YX, Zhao H, Cao RY, Deng YQ, Han JF, Zhu SY, Qin CF. 2014. 603 Recombinant tandem multi-linear neutralizing epitopes of human enterovirus 71 604 elicited protective immunity in mice. Virology journal 11(1): 79 DOI 605 10.1186/1743-422X-11-79

606 Liu Y, Huang H. 2018. Expression of single-domain antibody in different systems. 607 Applied microbiology and biotechnology 102(2): 539-551 DOI 10.1007/s00253$608 \quad$ 017-8644-3

609 Mahdy SE, Liu S, Su L, Zhang X, Chen H, Pei X, Wang C. 2019. Expression 610 of the VP1 protein of FMDV integrated chromosomally with mutant Listeria 611 monocytogenes strain induced both humoral and cellular immune responses.

612 Applied microbiology and biotechnology 103(4): 1919-1929 DOI 613 10.1007/s00253-018-09605-x

614 Mansouri M, Mousavy SJ, Ehsaei Z, Nazarian S, Zali MR, Moazzeni SM. 615 2013. The codon-optimization of cfaE gene and evaluating its high expression 616 capacity and conserved immunogenicity in Escherichia coli. Biologicals 41(3): 617 169-175 DOI 10.1016/j.biologicals.2013.01.002 
618 Mordecai GJ, Wilfert L, Martin SJ, Jones IM, Schroeder DC. 2016. Diversity 619 in a honey bee pathogen: first report of a third master variant of the Deformed 620 Wing Virus quasispecies. The ISME journal 10(5): 1264 DOI $621 \quad \mathbf{1 0 . 1 0 3 8 / \text { ismej.2015.178 }}$

622 Natsopoulou ME, Mc Mahon DP, Doublet V, Frey E, Rosenkranz P, Paxton 623 RJ. 2017. The virulent, emerging genotype B of Deformed wing virus is closely 624 linked to overwinter honeybee worker loss. Scientific reports 7(1): 5242 DOI $625 \quad \mathbf{1 0 . 1 0 3 8 / \mathbf { s } 4 1 5 9 8 - 0 1 7 - 0 5 5 9 6 - 3}$

626 Nieuwkoop T, Claassens NJ, van der Oost J. 2019. Improved protein production 627 and codon optimization analyses in Escherichia coli by bicistronic design. 628 Microbial biotechnology 12(1): 173-179 DOI 10.1111/1751-7915.13332

629 Ojha R, Nandani, R, Prajapati VK. 2019. Contriving multiepitope subunit 630 vaccine by exploiting structural and nonstructural viral proteins to prevent 631 Epstein-Barr virus - associated malignancy. Journal of cellular physiology 234(5): 632 6437-6448 DOI 10.1002/jcp.27380

633

634

635 Škubník K, Nováček J, Füzik T, Přidal A, Paxton RJ, Plevka P. 2017. 636 Structure of deformed wing virus, a major honey bee pathogen. Proceedings of the 637 National Academy of Sciences 114(12): 3210-3215 DOI 638 10.1073/pnas.1615695114

639 Stachyra A, Redkiewicz P, Kosson P, Protasiuk A, Góra-Sochacka A, Kudla 640 G, Sirko A. 2016. Codon optimization of antigen coding sequences improves the 641 immune potential of DNA vaccines against avian influenza virus H5N1 in mice 642 and chickens. Virology journal 13(1): 143-153 DOI 10.1186/s12985-016-0599-y

643 Sun H, Li J, Liu GZ, Yin K, Cui Y, Xiao T, Wei QK. 2017. Expression of 644 codon-optimized TgMIC16 in three Escherichia coli strains. 3 Biotech 7(4): 270 645 DOI 10.1007/s13205-017-0885-4

646 Sun L, Li M, Fei D, Wang J, Li L, Mingxiao M. 2018. Preparation and 647 application of egg yolk antibodies against Chinese sacbrood virus infection. 648 Frontiers in microbiology 9: 1814 DOI 10.3389/fmicb.2018.01814 
649 Tehel A, Vu Q, Bigot D, Gogol-Döring A, Koch P, Jenkins C, Paxton R. 2019.

650 The Two Prevalent Genotypes of an Emerging Infectious Disease, Deformed Wing 651 Virus, Cause Equally Low Pupal Mortality and Equally High Wing Deformities in 652 Host Honey Bees. Viruses 11(2): 114 DOI 10.3390/v11020114

653 Tian J, Yan Y, Yue Q, Liu X, Chu X, Wu N, Fan Y. 2017. Predicting 654 synonymous codon usage and optimizing the heterologous gene for expression in $E$. 655 coli. Scientific reports 7(1): 9926 DOI 10.1038/s41598-017-10546-0

656 Wang H, Shan S, Wang S, Zhang H, Ma L, Hu L, Zhu, R. 2017. Fused IgY Fc 657 and Polysaccharide Adjuvant Enhanced the Immune Effect of the Recombinant 658 VP2 and VP5 Subunits-A Prospect for Improvement of Infectious Bursal Disease 659 Virus Subunit Vaccine. Frontiers in microbiology 8: 2258 DOI $660 \quad 10.3389 /$ fmicb.2017.02258

661 Wang Q, Mei C, Zhen H, Zhu J. 2012. Codon preference optimization increases 662 prokaryotic cystatin expression. Journal of Biomedicine and Biotechnology 2012: 663732017 DOI 10.1155/2012/732017

664 Xie Y, Li H, Qi X, Ma Y, Yang B, Zhang S, Li Z. 2019. Immunogenicity and 665 protective efficacy of a novel foot-and-mouth disease virus empty-capsid-like 666 particle with improved acid stability. Vaccine 37(14): 2016-2025 DOI 667 10.1016/j.vaccine.2019.02.032

668 Yin L, Chen L, Luo Y, Lin L, Li Q, Du Y, Zhou Q. 2019. Recombinant fiber-2 669 protein protects Muscovy ducks against duck adenovirus 3 (DAdV-3). Virology 670 526: 99-104 DOI 10.1016/j.virol.2018.10.011

671 Zhao Y, Heerman M, Peng W, Evans JD, Rose R, DeGrandi-Hoffman G, Su S. 672 2019. The dynamics of Deformed wing virus concentration and host defensive 673 gene expression after varroa mite parasitism in honey bees, Apis mellifera. Insects 674 10(1): 16 DOI 10.3390/insects10010016

675 Zheng B, Lou D, Ding J, Zhuo X, Ding H, Kong Q, Lu S. 2019. GRA24-Based 676 DNA Vaccine Prolongs Survival in Mice Challenged With a Virulent Toxoplasma 677 gondii Strain. Frontiers in immunology 10: 418 DOI 10.3389/fimmu. 2019. $678 \quad 00418$

679 


\section{Figure 1}

Expression and purification of the recombinant proteins by SDS-PAGE analysis in E.coli.

$A, B$, and $C$ represent the recombinant proteins roVP1, roVP2, and roVP3, respectively. Lane 1; protein weight marker. Lane 2-4; induced E. coli BL21 (DE3) of the corresponding plasmids after $6 \mathrm{~h}$ with $0.1 \mathrm{mM}, 0.25 \mathrm{mM}$, and $0.5 \mathrm{mM}$ IPTG, respectively. Lane 5, uninduced $E$. coli BL21 (DE3) of the corresponding plasmids as control. Lane 6; purification of the corresponding recombinant proteins.

A

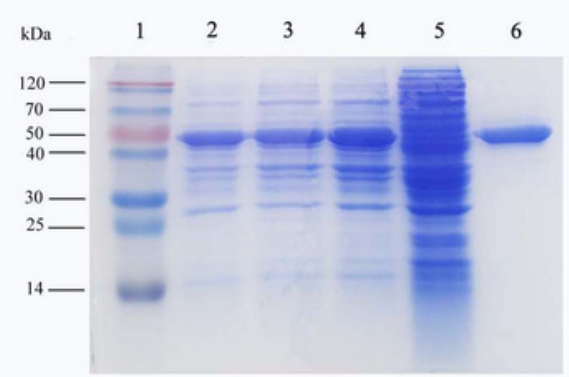

B

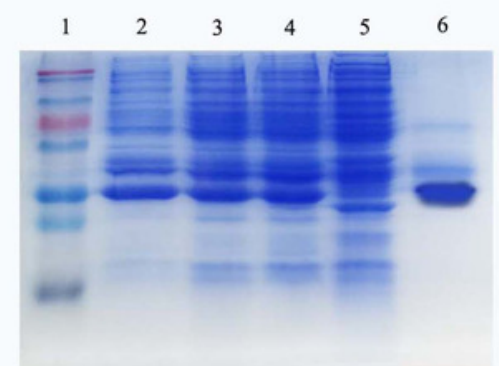

$\mathrm{C}$

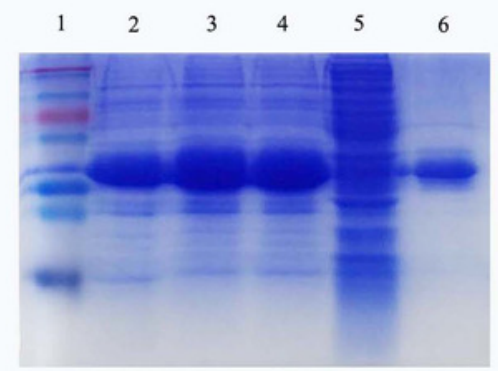




\section{Figure 2}

Western blot identification of the recombinant proteins with the anti-His tag antibody and mouse anti-DWV polyclonal antibody.

$A, B$, and $C$ represent roVP1, roVP2, and roVP3, respectively. Lane 1 ; anti-His tag antibody was used as primary antibody. Lane 2; mouse anti-DWV polyclonal antibodies as primary antibody. Lane 3; negative control (NC), the serum of healthy mice.

A

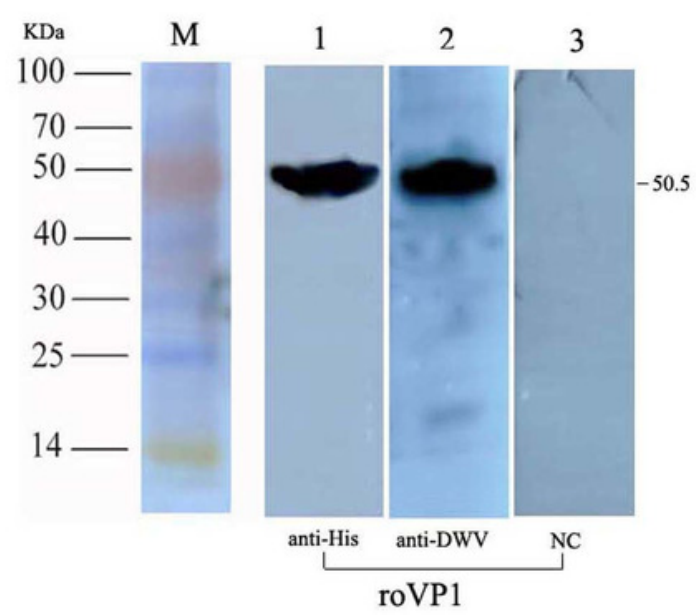

B

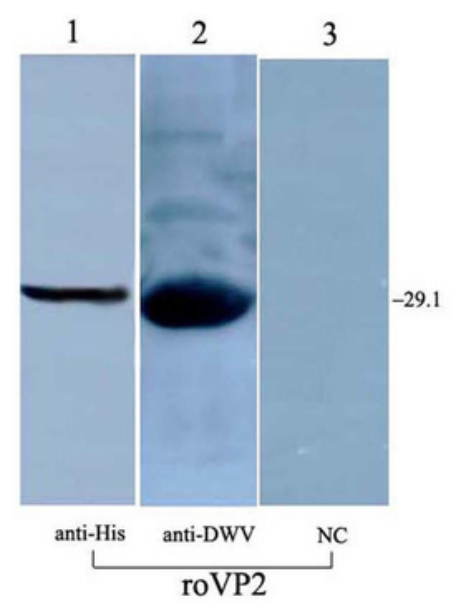

$\mathrm{C}$

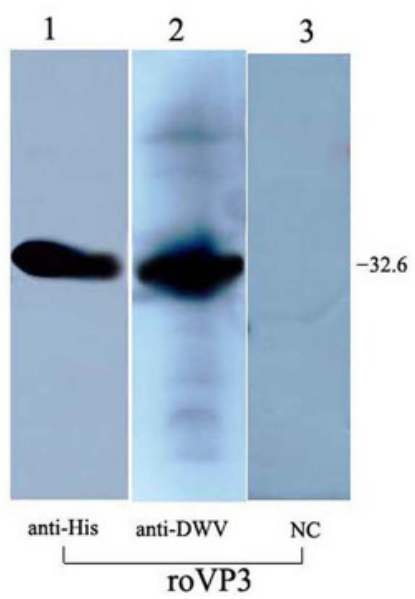


Figure 3

Specific IgG antibodies in serum of the immunized mice

The $\mathrm{OD}_{450}$ value of total $\lg \mathrm{G}$ were detected on $0,2,4$, and 6 weeks post-vaccination. Data are expressed as the mean $\pm S D(n=5)$ values. *Significantly different compared with the control group $(P<0.05)$.* Significant differences between three groups immunized with recombinant proteins $(P<0.05)$.

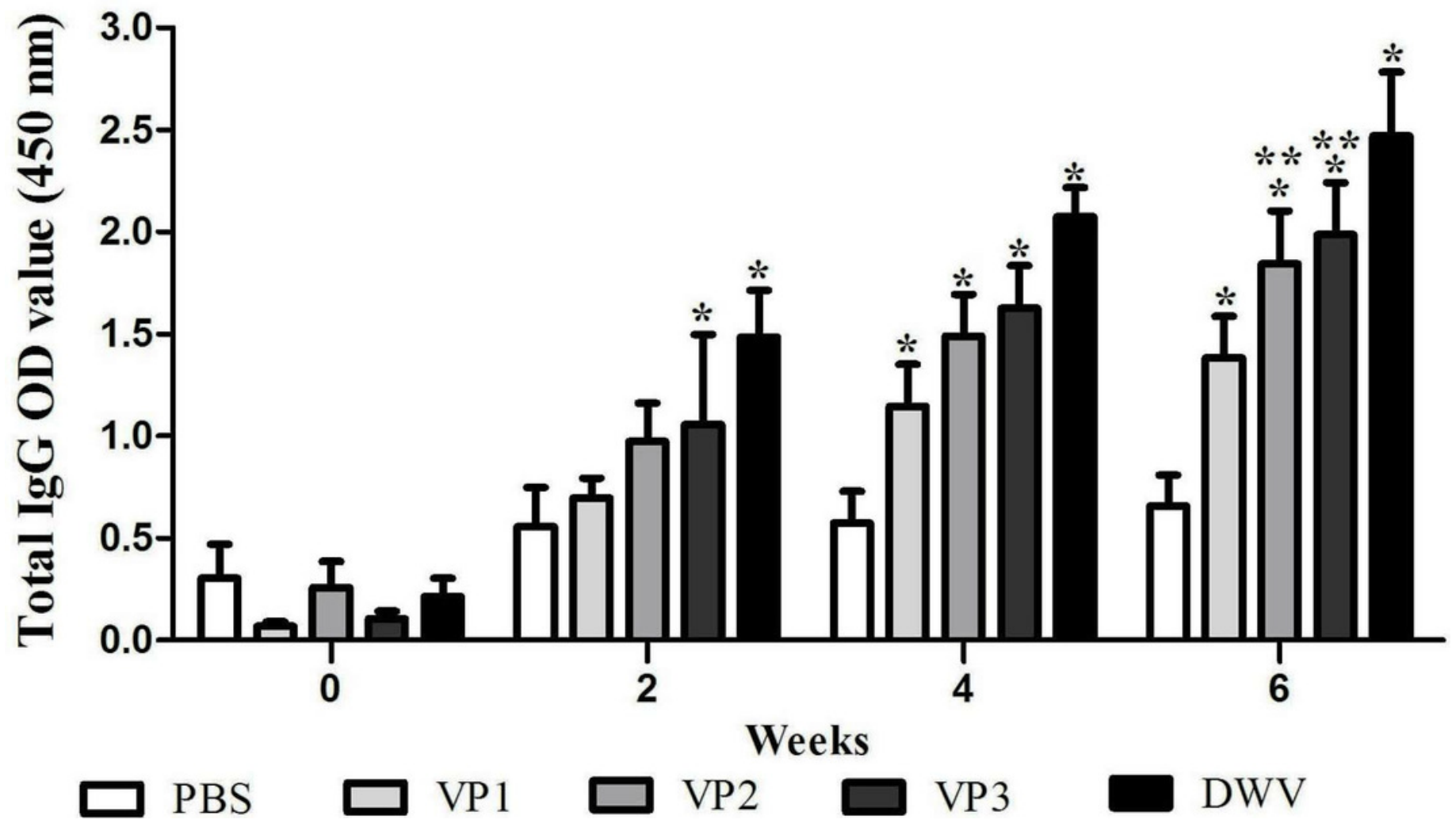


Figure 4

Lymphocyte proliferation responses of immunized mice

The value of Stimulation index (SI) were calculated at 6 weeks post-vaccination. Data are expressed as the mean $\pm S D(n=5)$ values. *Significantly different than the control group $(P<0.05)$.

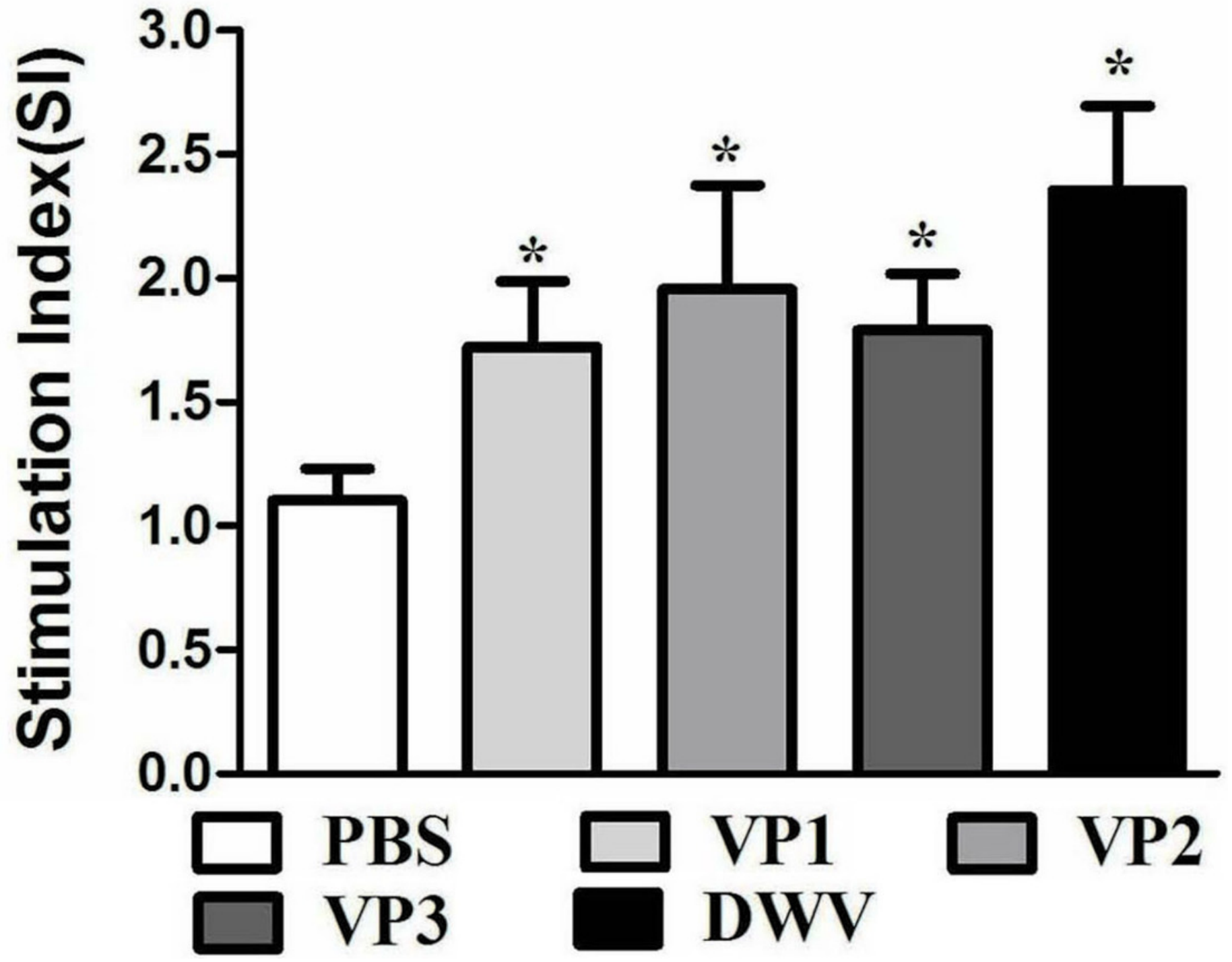


Figure 5

Cytokine response in sera of immunized mice

$A, B, C$ and $D$ represent the levels of cytokines IL-2, IL-4, IL-10, and IFN- $\gamma$ by ELISA, respectively. Data are expressed as the mean $\pm S D(n=5)$ values. *Significantly different compared with the control group $(P<0.05) . * *$ Significant differences between three groups immunized with recombinant proteins $(P<0.05)$.

A

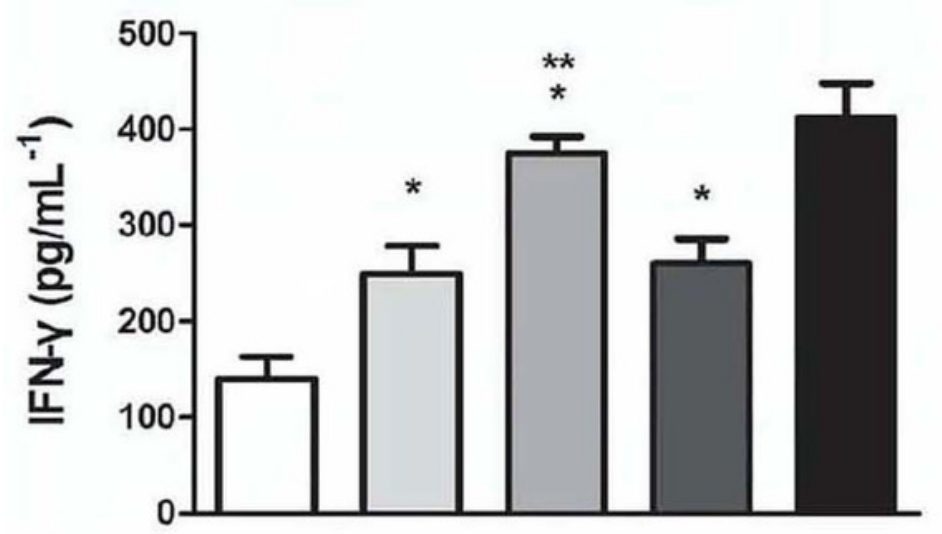

$\mathrm{C}$

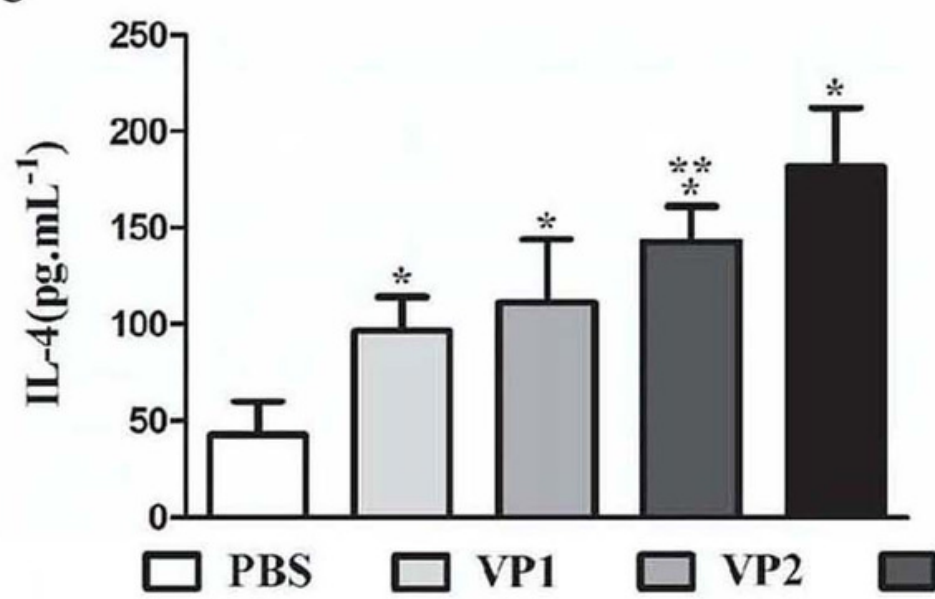

B

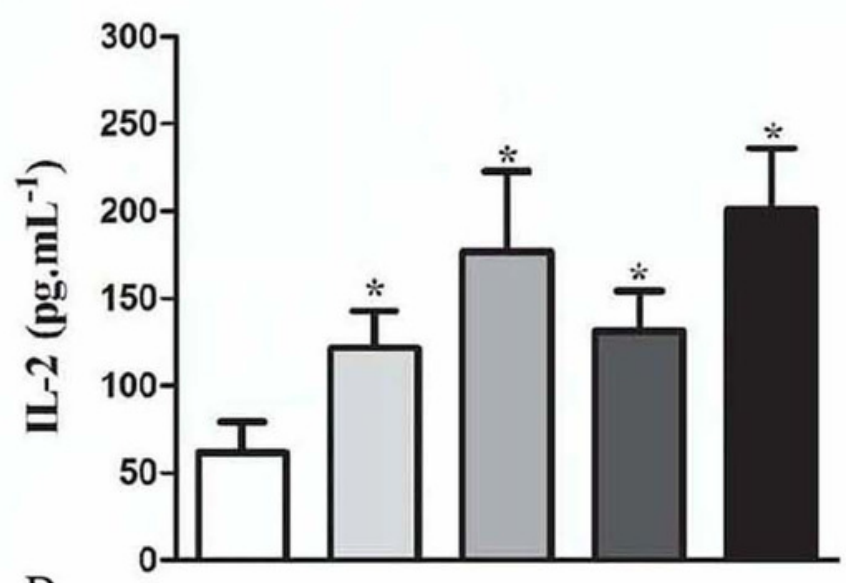

$\mathrm{D}$

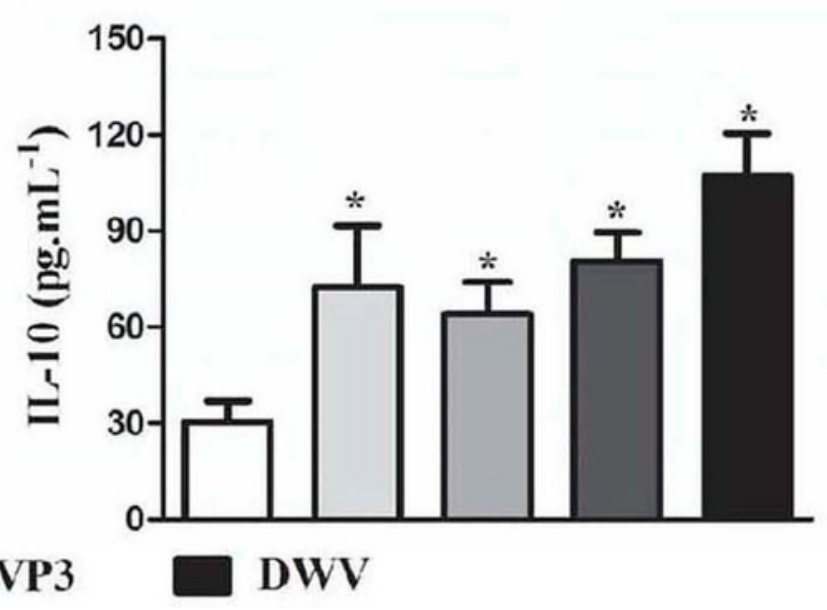




\section{Figure 6}

Relative normalized DWV of the honeybee pupae

The quantification of DWV titer in the samples was performed by the real time qRT-PCR, and the relative normalized DWV titer was determined as the DWV titer after normalization with the reference gene Actin, and the relative DWV titers of the pupae were assessed by calculating delta $\mathrm{Ct}$ values $\left(\Delta \mathrm{Ct}=\mathrm{C} t_{(\mathrm{DWv})}-\mathrm{C} t_{(\text {actin) }}\right)$.*Significantly different compared with the virus-only group $(P<0.05)$.**Significant differences between three groups immunized with recombinant proteins $(P<0.05)$. 


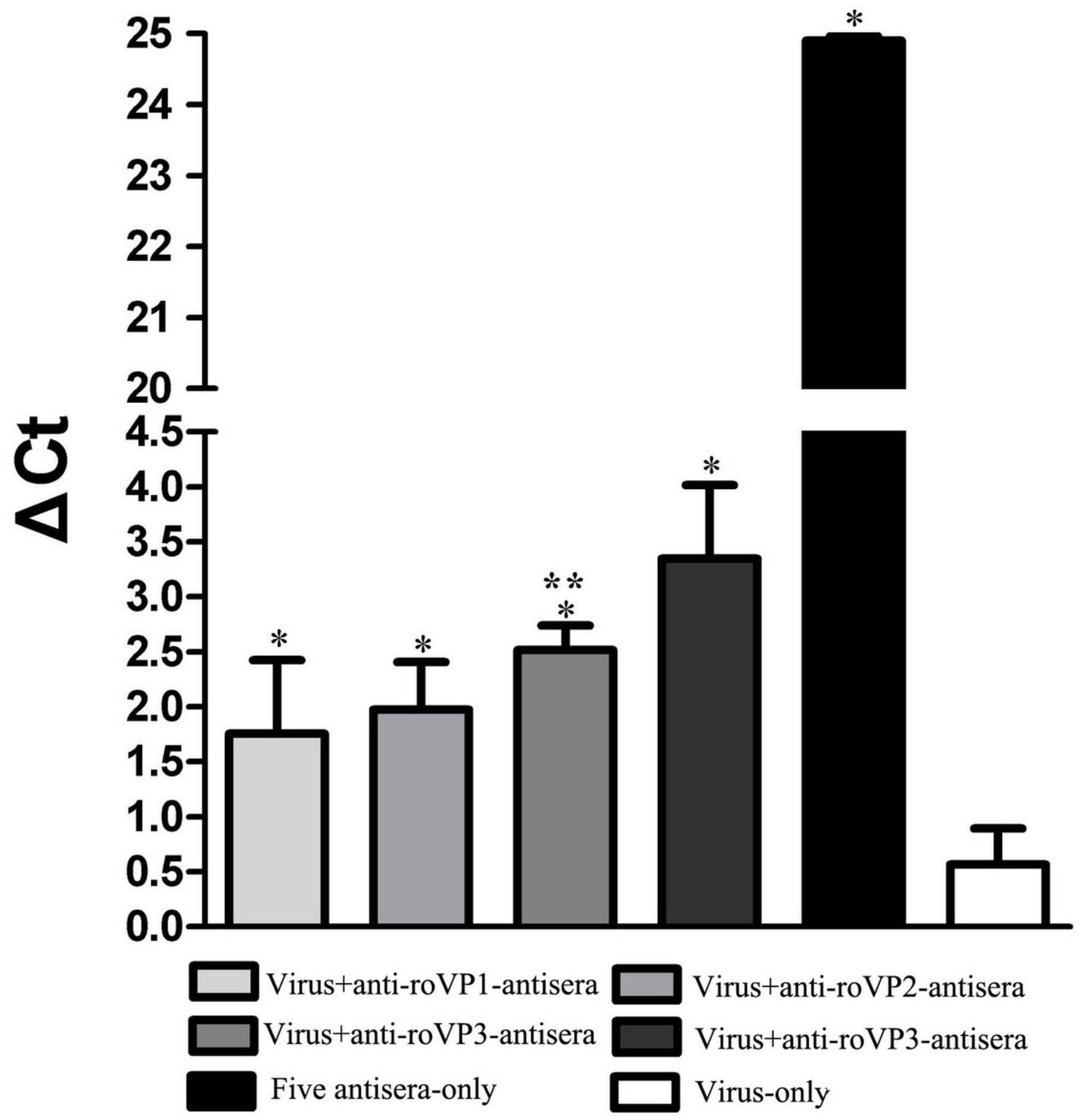

